OCCASIONAL PAPER

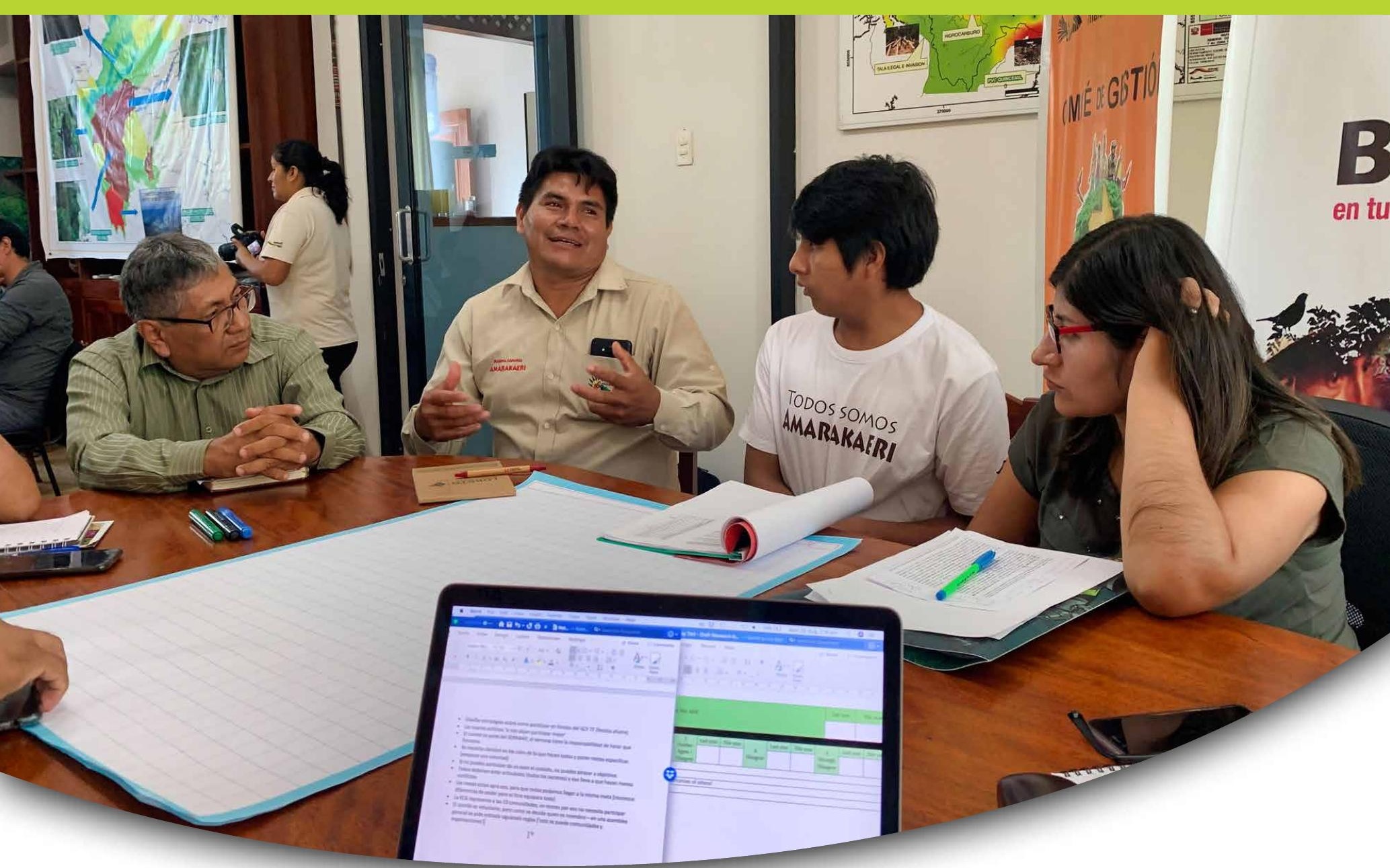

\title{
Intensity and embeddedness
}

Two dimensions of equity approaches in multi-stakeholder forums

Christopher Hewlett

Juan Pablo Sarmiento Barletti

Anne M Larson

Nicole Heise Vigil

Natalia Cisneros

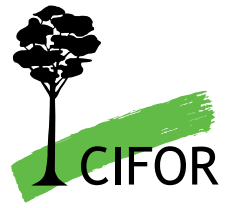

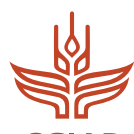

CGIAR
RESEARCH

PROGRAM ON

Policies,

Institutions,

and Markets
RESEARCH

PROGRAM ON

Forests, Trees and Agroforestry 



\title{
Intensity and embeddedness
}

Two dimensions of equity approaches in multi-stakeholder forums

\author{
Christopher Hewlett \\ University of Sussex \\ Juan Pablo Sarmiento Barletti \\ CIFOR \\ Anne M Larson \\ CIFOR \\ Nicole Heise Vigil \\ CIFOR
}

Natalia Cisneros

CIFOR 
Occasional Paper 221

(c) 2021 Center for International Forestry Research

(c) (1) Content in this publication is licensed under a Creative Commons Attribution 4.0 International (CC BY 4.0), http://creativecommons.org/licenses/by/4.0/

ISBN 978-602-387-157-5

DOI: $10.17528 /$ cifor/008003

Hewlett C, Sarmiento Barletti JP, Larson AM, Heise Vigil N and Cisneros N. 2021. Intensity and embeddedness: Two dimensions of equity approaches in multi-stakeholder forums. Occasional Paper 221. Bogor, Indonesia: CIFOR.

Photo by Juan Pablo Sarmiento Barletti/CIFOR

Amarakaeri Communal Reserve MSF - Monitoring tool development.

\author{
CIFOR \\ Jl. CIFOR, Situ Gede \\ Bogor Barat 16115 \\ Indonesia \\ $\mathrm{T}+62(251) 8622-622$ \\ $F+62(251) 8622-100$ \\ E cifor@cgiar.org
}

\title{
cifor.org
}

We would like to thank all donors who supported this research through their contributions to the CGIAR Fund. For a list of Fund donors, please see: http://www.cgiar.org/about-us/our-funders/.

Any views expressed in this publication are those of the authors. They do not necessarily represent the views of CIFOR, the editors, the authors' institutions, the financial sponsors or the reviewers. 


\section{Contents}

Acknowledgments $\quad$ v

Summary vi vi vis

1 Introduction 1

2 Case studies and methods $\quad 4$

3 Analysis 7

3.1 Hekluskogar, Iceland - Intensity: nominal / Embeddedness: nominal 7

3.2 Finger Lakes National Forest, USA - Intensity: low / Embeddedness: nominal 7

3.3 Rural Fire Service-mandated MSF, Australia - Intensity: nominal /

Embeddedness: nominal $\quad 8$

3.4 Advisory Council on Conflict Resolution and REDD+, Panama -
Intensity: low / Embeddedness: low

3.5 Juma Sustainable Development Reserve Project, Brazil - Intensity: low /
Embeddedness: medium

3.6 Yalova Model Forest, Turkey - Intensity: low / Embeddedness: medium 10

3.7 Hin Nam No Protected Area, Lao PDR - Intensity: medium /
Embeddedness: medium

3.8 Bangkok Urban Green Space, Thailand - Intensity: medium /

3.9 Ashaninka Communal Reserve, Peru - Intensity: medium / Embeddedness: high 12

3.10 Dwebe Project, South Africa - Intensity: low / Embeddedness: medium 13

3.11 The Makuleke Claim, South Africa - Intensity: low / Embeddedness: medium 13

3.12 Agama Forest Cooperative, Ethiopia - Intensity: medium / Embeddedness: high 14

3.13 Ntchisi Forest Reserve, Malawi - Intensity: high / Embeddedness: high 15

4 Discussion $\quad 18$

4.1 The outcome of the combination of different degrees of intensity and
embeddedness depends on the context in which MSFs are implemented

4.2 There are limited data on processes, outcomes and medium- and long-term
impacts of MSFs, highlighting the need to publish more details

$\begin{array}{ll}4.3 & \text { Lessons for methods and research processes } \\ & 20\end{array}$

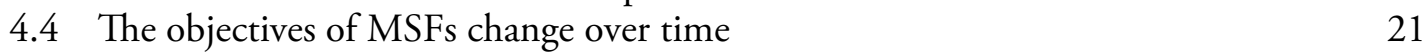

4.5 Implementation matters - Designing a participatory process to be equitable
is not enough

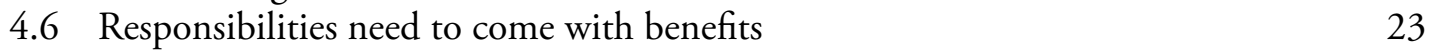

5 Concluding remarks $\quad 24$

$\begin{array}{ll}\text { References } & 25\end{array}$ 


\section{List of figures and tables}

\section{Figures}

1 Intensity and embeddedness of approaches to equity 5

2 Visual summary of intensity and embeddedness by case study 19

\section{Tables}

1 Case studies

2 Indicators for different levels of intensity and embeddedness

6

3 Classification of MSF case studies based on their intensity

4 Classification of MSF case studies based on their embeddedness 


\section{Acknowledgments}

The authors would like to thank reviewers Blake Ratner and Jesse Ribot for their help in improving this occasional paper. Funding support for this study was provided by the Norwegian Agency for Development Cooperation; the European Commission; the International Climate Initiative of the German Federal Ministry for the Environment, Nature Conservation and Nuclear Safety; and the United Kingdom's Department for International Development. This work was undertaken as part of the CGIAR Research Program on Policies, Institutions, and Markets (PIM), led by the International Food Policy Research Institute (IFPRI), and the CGIAR Research Program on Forests, Trees and Agroforestry (FTA), led by CIFOR. The opinions expressed here are those of the authors, and do not necessarily reflect the views of IFPRI, CIFOR, CGIAR or the donors. 


\section{Summary}

Multi-stakeholder forums (MSFs) have been positioned as a transformative solution for more sustainable decision-making in forestry, land use, and climate change interventions. Based on a review of 13 cases in the scholarly literature, this occasional paper presents a new approach to examining how MSFs on land use and land-use change address equity. We engage with MSFs from two key characteristics: the degree to which an MSF includes local peoples as part of a forest-landscape solution (its intensity), and the degree to which the MSF and its outcomes are part of the societal and institutional fabric of a given area (its embeddedness). The reason for focusing on these aspects is simple yet important: we propose that an MSF's resilience and potential to promote equity is impeded if local peoples are not regarded as key partners and change-makers (rather than 'beneficiaries'), and if the forum and/or its outcomes are not meaningfully institutionalized. Intensity and embeddedness are useful analytical tools that go beyond typologies that identify characteristics found in successful MSFs. They are helpful in terms of explaining how different approaches across different contexts function and add nuance to simplified dichotomies. 


\section{Introduction}

Multi-stakeholder forums (MSFs) have been positioned as a transformative solution for more sustainable decision-making in forestry, land use and climate change interventions (Gonsalves et al. 2005; Bastakoti and Davidsen 2015; Larson et al. 2018). These forums are sometimes referred to as multi-stakeholder initiatives (Kohne 2014), networks (Brummel et al. 2012), partnerships (Backstrand 2006), processes (Hemmati et al. 2002), platforms (Faysse 2006; Warner 2006), regulation initiatives (Haufler 2003), governance arrangements (Schouten et al. 2012) and nongovernmental systems of regulation (O'Rourke 2006). Their popularity is driven by the recognition that environmental challenges are complex and multi-dimensional, as is the array of actors with multiple interests in land use and land-use policy and practice (Poncelet 2004; Gray and Purdy 2018). This interest is also reflected in donors' requirements for project funding. However, despite increasing interest and funding to support platforms in achieving more equitable and effective participatory processes, there is little comparative research on the topic. Furthermore, existing data on the track record for MSFs in accomplishing meaningful participation and conservation or sustainability are mixed. Moreover, recent research suggests that such platforms rarely address the underlying issues of equity, such as inclusion and unequal power relations, a key dimension of the MSF approach (Ravikumar et al. 2018; Sarmiento Barletti et al. 2020). Measuring their effectiveness has also proven to be a challenge (Sterling et al. 2017).

This article builds on prior research by the authors (Hewlett n.d.; Sarmiento Barletti et al. 2019, 2020; Sarmiento Barletti and Larson 2019a). Based on a review of cases in the scholarly literature, it contributes to closing this evidence gap by presenting a new approach to examining how MSFs on land use and land-use change address equity. This approach engages with MSFs around two key dimensions: their intensity and their embeddedness.

We define intensity as the degree to which an MSF includes local peoples as part of a forest-landscape solution. Intensity is about the internal focus on and structure of the MSF for increasing peoples' participation, and understanding, targeting and addressing identified inequalities. This is the extent to which attention, resources and creative methods are designed and used to promote structural changes in the target population. This is exemplified in the intensity with which the MSF intends to facilitate the transfer of power to local communities or other groups that have been excluded from power-sharing processes. As we understand it, intensity combines two different aspects of MSFs: social inclusion in its processes and whether the forum aims to equitably distribute different aspects of power (e.g. access to participation, land and resources, decision-making and equal respect for different kinds of knowledge) among stakeholders. Thinking through intensity allows us to gauge an MSF's explicit focus and position it with respect to others, based on its emphasis on empowerment, increasing equity, and actions toward addressing structural inequalities. For example, a low-intensity MSF might aim to empower marginalized people by having more powerful actors listen to and learn from them but include nothing explicitly related to addressing power inequalities. A high-intensity MSF might seek to address power inequalities by including local knowledge in discussions that had previously been held in 'technical' terms, as well as ensuring rights to land and resources for Indigenous Peoples and women within that group.

In evaluating and determining each MSF's degree of intensity, we will explore the following questions:

- To what extent is the MSF designed with a focus on addressing inequalities and 
emphasizing empowerment in and beyond the internal process of the forum?

- To what extent do organizers or participants base their own success on increasing involvement and empowerment of marginalized groups?

- To what extent are the goals of the MSF to bring about structural or institutional changes in conditions of inequality, access to resources and power over decision-making?

We define embeddedness as the degree to which an MSF and/or its goals or objectives are embedded or entangled in wider societal or governmental programs and processes. This engages with the breadth of the project within which an MSF is situated. In some cases, an MSF stands alone and has a single, one-time objective. More often, MSFs are part of wider processes aiming to initiate environmental, economic, political, and/or social change. Whereas intensity focuses on an MSF's internal processes and goals, embeddedness contemplates the context in which the MSF operates and the formal and/ or informal institutions and structures that can either hinder or promote the MSFs in bringing about positive change. It offers a way to classify different MSFs based on scale and connectivity to wider processes. Not all MSFs are embedded in wider projects, but many are - intentionally or unintentionally. Although an MSF's insertion may bring advantages, it is important to evaluate the different implications, opportunities and limitations of being embedded in wider projects and programs, including national-level policies, regional programs, other donor-funded projects and global goals. Thinking through embeddedness allows us to map the connections between an MSF and existing or planned policies, projects, programs, and government and social institutions and movements, and thus to understand an MSF's pathways or obstacles to impact.

In evaluating and determining each MSF's degree of embeddedness, we will explore the following questions:

- To what extent is the MSF part of a wider program and/or process?

- Is the MSF a short-term, problem-oriented body? Or is it a permanent institution?

- Is the relationship between an MSF and other programs and processes tangential, accidentally nested, significantly entangled, intentionally embedded or directly connected?
- If it is a permanent institution, to what degree does it control resources or funds? What degree of authority does it have, i.e. how much control does it have over decision-making?

The reason for focusing on these aspects is simple yet important: we propose that an MSF's resilience and potential to promote equity are impeded if local peoples are not regarded as key partners and change-makers (rather than 'beneficiaries') and if the forum and/or its outcomes are not meaningfully institutionalized. We prioritize these concerns for a number of reasons. First, MSFs are specifically designed to be participatory processes; hence, any understanding of how they work must include an exploration of who participates, how and with what results. Second, participation in an MSF has a particular intent, depending on the assumptions of those who design it. In a recent review, Sarmiento Barletti et al. (2020) identified four different 'program theories' that sought local 'buy-in' to MSFs using different primary levers: sustainability, economic benefits, co-management and multilevel coordination. Thus, local people's participation is seen as essential for on-the-ground changes, but approaches vary. Third, although MSFs commonly involve different stakeholders - government, private sector, non-governmental organizations (NGOs) - this article prioritizes inclusion and empowerment of Indigenous Peoples and local communities, women and youth. These groups have been recognized as being most at risk from climate change and large-scale land-use changes, as well as efforts to address the latter (Adger 2006; IPCC 2007; Tsosie 2007). Concerns for the underrepresentation of these vulnerable groups emerge from our own research (Larson et al. 2018; Sarmiento Barletti and Larson 2020). They are also highlighted in global priorities, such as the Sustainable Development Goals, and international agreements recognizing rights to self-determination and free, prior and informed consent, such as the International Labour Organization Covenant 169 (ILO 1989) and the United Nations Declaration on the Rights of Indigenous Peoples (UN 2007).

Finally, there are not enough systematic data available to understand how MSFs work, how they are tied to empowerment and social change, or if and how they bring about positive land-use change outcomes. Our prior research found that more equitable and resilient MSFs need to shift away from designing projects to 'designing for 
engagement' in a way that works with people and addresses context (Sarmiento Barletti et al. 2020). However, understanding the impacts of such forums requires better analytical tools and their systematic application. The concepts developed here are intended to be a step in that direction.

In what follows, we develop an analytical framework for understanding these two key aspects of MSFs, intensity and embeddedness, based on 13 case studies chosen from an extensive literature review (see Sarmiento Barletti et al. 2020). The next section explains the methods and selection of cases. Section 3 presents each case and develops the analysis. This is followed by a discussion of the overall findings, as well as lessons regarding the analysis for understanding approaches to equity. The final section provides a short conclusion. 


\section{Case studies and methods}

The analysis that follows is based on a set of MSFs that address governance and management of forested landscapes at the subnational level and that involve both government and non-government participants. We define MSFs as "purposefully organized interactive processes that bring together a range of stakeholders to participate in dialogue, decisionmaking and/or implementation regarding actions seeking to address a problem they hold in common or achieve a goal for their common benefit" (Sarmiento Barletti and Larson 2019a, 1). Thirteen cases were chosen from the literature to explore the intensity and embeddedness of MSFs. These cases are not an exhaustive list of the different kinds of MSFs in the literature, but they do offer evidence to support the utility of our approach and offer insights into MSFs in general. The sample includes voluntary and statutory MSFs, which have varied aims including dialogue, negotiation, fostering trust, addressing disputes and conflicts, managing resources, collective decision-making and implementing solutions. As this variety suggests, MSFs do not necessarily fall under a neat definition: after all, their multi-stakeholder nature is likely to prevent this. As Warner $(2006,9)$ notes, "an inventory of what [MSFs] should do turns out to be all things to all people". Furthermore, subnational MSFs were chosen for three reasons. First, prior to this project, recent analysis on MSFs focused primarily on international initiatives (e.g. the Roundtables on Responsible Soy and Sustainable Palm Oil). Second, subnational MSFs are closer to the geographical spaces and the stakeholders involved in and affected by land-use change, planning and management. Third, the analysis contributes to a growing interest in scholarship and practice on subnational jurisdictional approaches to tackle climate change and deforestation (Boyd et al. 2018; Stickler et al. 2018).

The 13 case studies were selected following an inclusion criterion beyond the baseline criteria set out above - subnational MSF with at least one government and one non-government participant. They were chosen to represent different kinds of MSFs that were identified from the research carried out toward a realist synthesis review of subnational MSFs that considered almost 1000 articles (Sarmiento Barletti et al. 2020; see Sarmiento Barletti et al. 2019 for the protocol). The case studies are indicative of wider trends in the literature that were identified in the review. Beyond this, the cases were chosen following two additional criteria. First, they included sufficient material to understand how the processes work allowing their intensity and embeddedness to be evaluated. Second, the cases included data on how MSFs can change over time and how these shifts impacted their processes and outcomes.

The literature on MSFs is expansive and covers a wide range of issues. Thus, delineating the parameters of projects, identifying their primary objectives, assessing their internal success and evaluating wider impacts is complicated. This is further complicated by the connection of many (if not most) projects to wider agendas and funding. Table 1 includes basic information for our 13 case studies and an assignment of their degrees of intensity and embeddedness on a scale from nominal (lowest), low, medium, to high (highest). Table 2 presents the set of indicators for the different levels of intensity and embeddedness in order to evaluate the case studies. These attributes and characteristics are not meant to be exhaustive but represent key trends identified in the literature and in prior research by the authors (Sarmiento Barletti and Larson 2019b; Sarmiento Barletti et al. 2020).

In the next section, we present a summary for each MSF and explain the different ratings given for intensity and embeddedness for each case (illustrated in Figure 1). In brief,

- MSFs with low levels of intensity and embeddedness (LI/LE) have a limited scope of participation, focus on a single issue and tend 
to be tangentially related to wider projects or programs as they are coincidentally nested in them without prior planning.

- MSFs with a high level of intensity but low level of embeddedness (HI/LE) address power inequalities inside the MSF, give significant emphasis to inclusivity and empowerment, and have high levels of participation. However, they do not allow for structural changes, as they are tangentially related to wider programs or projects, and are coincidentally nested in them without prior planning.

- In contrast, some MSFs have low levels of intensity but high levels of embeddedness (LI/ $\mathrm{HE})$. These low levels of intensity are reflected in an MSF's limited scope for participation, limited level of local control over processes and/or decision-making, and lack of legally binding agreements. However, the high level of embeddedness allows for integration with multilevel governance processes, the recognition and/or devolution of rights and responsibilities, and structural and institutional change. These MSFs are created or formalized by governance institutions, and they are intentionally embedded and/or directly connected to wider projects or programs.

- Finally, MSFs with high levels of intensity and embeddedness (HI/HE) allow structural and institutional changes, and are characterized by high levels of participation, significant emphasis on inclusivity and a focus on empowerment. They are integrated with multilevel governance processes and intentionally embedded and/or directly connected to wider projects or programs. They are created or formalized by governance institutions. These MSFs also recognize and devolve rights and corresponding responsibilities.
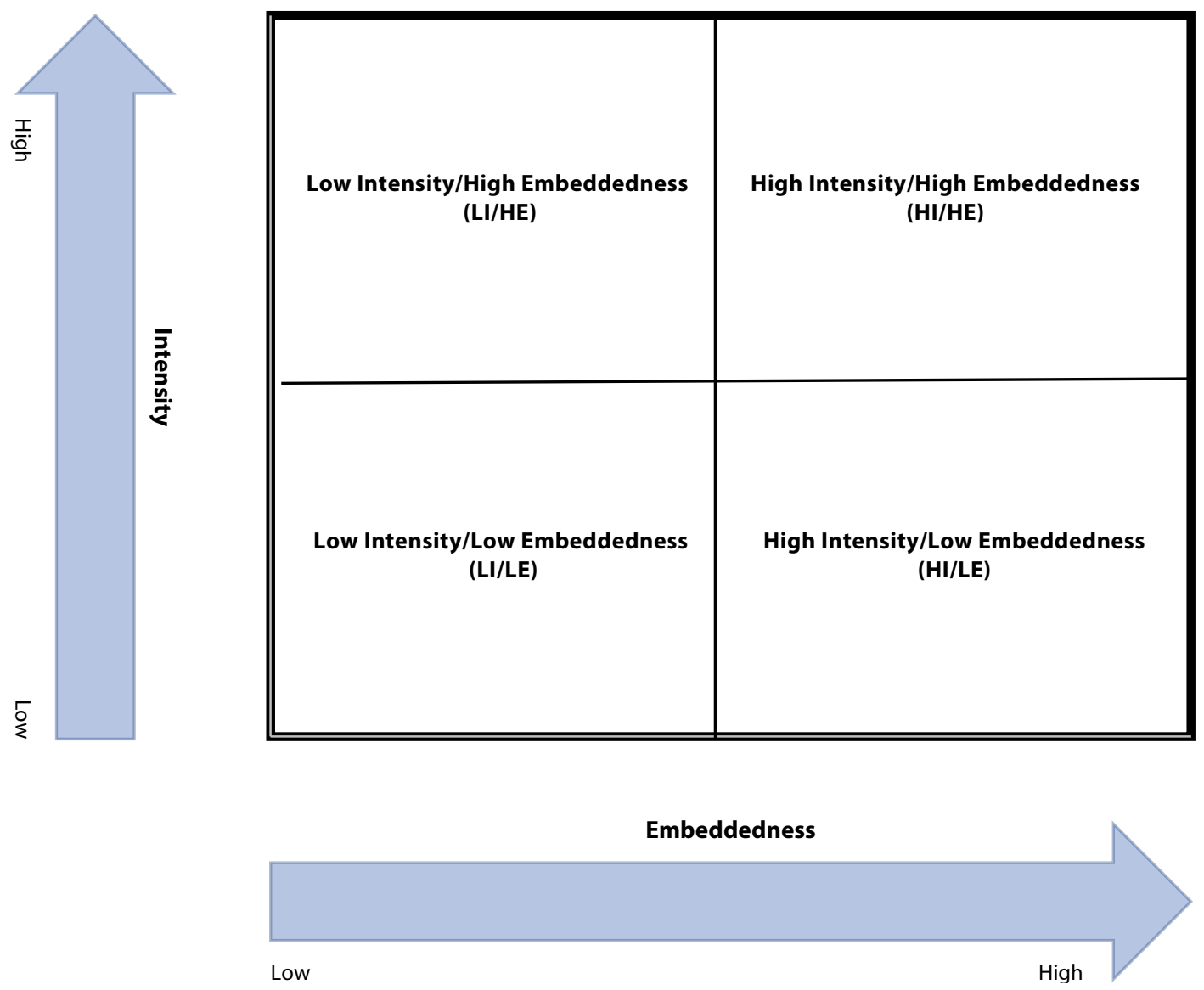

Figure 1. Intensity and embeddedness of approaches to equity 
Table 1. Case studies

\begin{tabular}{lllll}
\hline Case Study & Short title & Source & Intensity & Embeddedness \\
\hline Hekluskogar, Iceland & Hekluskogar & Berglund et al. 2013 & Nominal & Nominal \\
\hline Finger Lakes National Forest & Finger Lakes & Twarkins et al. 2001 & Low & Nominal \\
\hline New South Wales, Australia & NSW & Brummel et al. 2012 & Nominal & Nominal \\
\hline Embera Community, Panama & Embera & Holmes et al. 2017 & Nominal & Low \\
\hline Juma REDD+ Project, Brazil & Juma & Agustsson et al. 2014; & Low & Medium \\
\hline Yalova Model Forest, Turkey & Galoya & Bekiroglu et al. 2016 & Low & Medium \\
\hline Hin Nam No Protected Area, Lao PDR & Him Nam No & de Koning et al. 2017 & Medium & Medium \\
\hline Bangkok Urban Green Space, Thailand & Bangkok & Stringer et al. 2006 & Medium & Medium \\
\hline Ashaninka Communal Reserve, Peru & Ashaninka & Caruso 2011 \& 2014 & Medium & High \\
\hline Dwebe Project, South Africa & Dwebe & Fay 2014 & Low & Medium \\
\hline Makuleke Claim, South Africa & Makuleke & Fay 2014 & Low & Medium \\
\hline Agama Forest Cooperative, Ethiopia & Agama & Behagel et al. 2017 & Medium & High \\
\hline Ntchisi Forest Reserve, Malawi & Ntchisi & Zulu 2013 & High & High \\
\hline
\end{tabular}

Table 2. Indicators for different levels of intensity and embeddedness

\begin{tabular}{|c|c|c|}
\hline Value & Embeddedness & Intensity \\
\hline \multirow{7}{*}{ Nominal } & Focused on a single issue & Voluntary participation \\
\hline & Tangential & Limited scope for increasing inclusion \\
\hline & Accidentally nested & No mention of inequalities \\
\hline & Connection to single-issue policies and guidelines & Short-term \\
\hline & & $\begin{array}{l}\text { Informal and non-binding conflict resolution, } \\
\text { problem-solving, }\end{array}$ \\
\hline & & Local knowledge not taken into account \\
\hline & & Emphasis on increasing participation \\
\hline \multirow{4}{*}{ Low } & Significantly entangled & Establishment of partnerships \\
\hline & Intentionally embedded & Coordination \\
\hline & Limited connection to wider policies and guidelines & Collaboration \\
\hline & & $\begin{array}{l}\text { Limited emphasis on equity and empowerment } \\
\text { and nominal recognition of rights }\end{array}$ \\
\hline \multirow{5}{*}{ Medium } & $\begin{array}{l}\text { Directly connected to wider policies and } \\
\text { guidelines }\end{array}$ & $\begin{array}{l}\text { Specific measures for inclusivity and increasing } \\
\text { participation }\end{array}$ \\
\hline & Integrated with multilevel processes of governance & Co-management \\
\hline & Creation or formalization of governance institutions & Some focus on equity and empowerment \\
\hline & & Negotiated restricted rights to resources \\
\hline & & Some resource sharing \\
\hline \multirow{7}{*}{ High } & Structural and institutional change & Focus on empowerment \\
\hline & $\begin{array}{l}\text { Embedded or connected with wider projects/ } \\
\text { programs focused on participation }\end{array}$ & Focus on addressing inequalities \\
\hline & $\begin{array}{l}\text { Changes in local participation in decision-making } \\
\text { and control over resources }\end{array}$ & $\begin{array}{l}\text { Recognition of some customary rights and } \\
\text { responsibilities }\end{array}$ \\
\hline & & Management ongoing \\
\hline & & Contractual and equitable partnership \\
\hline & & Binding \\
\hline & & Increase rights to resources \\
\hline
\end{tabular}




\section{Analysis}

In what follows, we present a summary for each case study and explain the intensity and embeddedness rating assigned to each case. The summaries do not include the detail of the original articles; we encourage readers to read those articles for more information. Tables 3 and 4 classify all case studies based on our system of valuation for intensity and embeddedness and give a summary of our classification. The tables bring together the key attributes and characteristics used to differentiate between the levels of intensity and embeddedness.

\subsection{Hekluskogar, Iceland - Intensity: nominal / Embeddedness: nominal}

Hekluskogar was initiated by the Soil Conservation Service of Iceland (SCSI) to restore woodlands in an area around Mt. Hekla in southern Iceland.

Intensity. In 2005, SCSI set up a Collaboration Committee, comprising local farmers, governmental agencies and NGOs, to promote the restoration of woodlands and plan future work. However, after government funding was secured, the Committee was transformed into an advisory board and a separate Executive Board comprised of SCSI and Iceland's Forest Department took charge of the project. Discontent emerged: farmers' expectations of involvement were not met as the Collaboration Committee was excluded from the project's management. The government retained control over the process, funding and decision-making. The SCSI shifted its policy to emphasize participation, with no effort to improve equity or increase rights for local people. This case has a 'nominal' intensity rating because it was implemented over a short period, did not include any binding agreements, had a limited scope for increasing inclusion and did not address inequalities.

Embeddedness. Overall, this case has a 'nominal' embeddedness rating as it was initiated by SCSI as a one-time mechanism that was tangential to its overall objectives in the region. SCSI, in response to growing awareness of the challenges of top-down decision-making approaches, began including participation in its projects in the early 1990s. Thus, when Hekluskogar began, it was embedded in a wider agenda to increase citizen participation in SCSI's work and build on grassroots momentum to secure funding from the central government. Hekluskogar's embeddedness is nominal given the lack of interconnection to and coordination with the broader community and government institutions. This differed greatly from how the program had been initially envisioned by local stakeholders and planned by the SCSI. In fact, there was sentiment among local stakeholders that the government had co-opted the momentum they had built.

\subsection{Finger Lakes National Forest, USA - Intensity: low / Embeddedness: nominal}

Finger Lakes is the only national forest in the State of New York. A core aspect of the National Parks Service is the development and implementation of forest plans which are updated every 10-15 years to meet the changing understandings and interests of stakeholders.

Intensity. Forest Service officials engaged with stakeholders to gather information about plans and issues regarding partnerships and ecosystem management. The aim was to guide the revision of forest plans through discussions and public meetings. In early meetings, Forest Service employees developed a list of issues to consider during plan revision. The Forest Service hosted Public Planning Group meetings where they disseminated packets of pertinent information to local stakeholders, reviewed existing plans, and raised further issues for the revision. The program succeeded in engaging with local stakeholders in terms of partnership. Furthermore, the 
participation of non-Forest Service facilitators encouraged participants to view the meetings as balanced, open and without pre-determined results. However, this case had a 'low' intensity rating because its mandate for participation had no emphasis on equity or increased rights for local people, it had a short time frame, and did not address inequalities or power differentials. Also, while the input of the local people and advocacy groups were accounted for in developing the landuse plan, it was ultimately guided by scientific recommendations and policy guidelines which do not emphasize equity.

Embeddedness. This case has a 'nominal' embeddedness rating. Although it was mandated by national-level policy, it was only mildly entangled with other ongoing processes, such as local advocacy for specific resource uses, and it was focused on a single issue (forest plans). The case has a relatively low level of embeddedness in terms of how it was embedded within and interconnected to other projects and networks. Overall, the effects of the interconnections with wider processes were narrow. Moreover, grassroots organizations or NGOs were not involved in organizing the process or directly engaging in decision-making. However, the MSF brought local groups closer together and created collaborative alliances among some of them.

\subsection{Rural Fire Service-mandated MSF, Australia - Intensity: nominal / Embeddedness: nominal}

This case deals with MSFs established and led by the New South Wales (NSW) Rural Fire Service in Australia. These forums were set up as part of a pilot program for cooperative and coordinated bushfire management. The aim was to increase local stakeholder participation and improve the planning and management of land with high risk for fires. The MSFs were established and led by the NSW Rural Fire Service.

Intensity. This case has a 'nominal' intensity rating because participation was voluntary, there was limited scope for increasing inclusion of marginalized groups, and there was no emphasis on addressing inequalities. In each area, a committee was established to collectively produce a Bush Fire Risk Management Plan every 5 years to minimize the impact of bushfires on life, property and the environment. The project stems from the New South Wales Rural Fires Act of 1997, which sets out a mandate to establish these committees in NSW's rural fire zones. This resulted in the creation of a formal institution that included the knowledge, interests and positions of different stakeholders. The MSF's primary goal was to increase the capacity of the Rural Fire Service and other stakeholders to prevent and manage fires, with no explicit focus on addressing inequalities or empowering local people. This case offers an example of a mandate for participation with little emphasis on equity or increased rights of local people.

Embeddedness. This case has a 'nominal' embeddedness rating; although the government mandated the inclusion of stakeholders, the planning process did not address inequalities. The inclusion of local people was intended to improve the data available to the Rural Fire Service and was not connected to any wider processes promoting equity and addressing inequalities. The process did not have the potential for impact beyond fire prevention and management, and there is no evidence of integration with other governmental processes or conservation projects. Furthermore, the authors argue that those central to and primarily responsible for the MSF avoided addressing power inequalities among stakeholders. This is evidenced in the method for gauging risk, which was asset focused and positioned property as central to the planning process, and in the Forest Service's development and control of the software used as the foundation for the plan. This resulted in an emphasis on expertise and technical knowledge, and on framing the discussion around the interests of those who owned or managed more land and assets. Thus, any attempt at building inclusiveness and addressing power differentials was undermined due to the failure to implement a methodology that coincided with or supported this overall goal. This demonstrates that mandating inclusion in and of itself is not necessarily sufficient.

\subsection{Advisory Council on Conflict Resolution and REDD+, Panama - Intensity: low / Embeddedness: low}
A REDD+ initiative was developed for the voluntary carbon market as part of a participatory 
action research project (2002-2014) in an Indigenous Embera community in Panama. As the research project grew, it was expanded to include avoided deforestation, livelihood improvements and the establishment of an MSF as a conflictresolution mechanism. Research was carried out as part of a wider collaborative project between the Embera community and McGill University's Neotropical Ecology Laboratory.

Intensity. This case stands out because it was built within a participatory action research project driven by a research center. From the outset, there was a focus upon empowering local people through a collaborative and reflexive learning approach. However, its REDD+ project component did not initially aim to increase equity within the community or between the community and the government or other stakeholders. People received support to enhance their livelihoods and support the protection of cultural heritage and traditional knowledge, but internal inequalities based on poverty, education or gender were not addressed. Organizers attempted to address power inequalities in the MSF, for example, through the establishment of an MSF to address land conflicts by promoting an intercultural and collaborative dialogue between the actors with territorial conflicts. Furthermore, there was little commitment among the government agencies to extend rights and decision-making power to local people. The informality and lack of binding agreements gives this MSF a low level of intensity.

Embeddedness. The main impediment to the MSF's development and success was the government's lack of support and engagement with a process that sought to identify solutions to problems regarding land conflicts that were under their jurisdiction. The MSF was embedded in and grew out of a wider participatory research project, was engaged with international norms, included involvement of different governmental agencies and sought to address land conflicts. As such, it was involved with multiple layers of institutional frameworks and interconnected with different social, political and economic processes at the regional, national and international levels. However, this connection was more theoretical than practical. Despite the connection to wider policies and international laws, actors with power over these policies were absent. The government's inability and/or unwillingness to engage with the process reduced the MSF's potential. Overall, the case has a 'low' embeddedness rating because it was not established with a government mandate or with the aim of formalizing customary rights. Despite having connections with wider policies and international laws, the absence of government actors with decision-making power reduced the effectiveness of these connections.

\subsection{Juma Sustainable Development Reserve Project, Brazil - Intensity: low / Embeddedness: medium}

This project was implemented in 2006 in Brazil's Amazonas state by the Sustainable Amazonas Foundation in partnership with Amazonas State Secretariat of the Environment and Sustainable Development. It was supported with financial aid from the Marriott International Hotel Group and technical aid from the Institute of Conservation and Sustainable Development of Amazonas. The project aimed to achieve zero net deforestation. It sought to offset the land-use restrictions from the introduction of the reserve by generating income for neighboring local communities by promoting sustainable businesses and direct cash transfers through Brazil's Bolsa Floresta Program.

Intensity. The program proposed the inclusion of local communities, but the plan for the project had already been developed when 'participatory meetings' were carried out. The project's approach was more about information sharing, than discussion and horizontal interaction. Interviewed community members felt disempowered after the process, and noted that benefits from the project were insufficient and that their food security and well-being were threatened. Furthermore, the payments for ecosystem services and evidence of targeting marginalized people responded to rules that were in place before the MSF, as Bolsa Floresta payments were designed to be given to women. Similarly, the project and MSF included programs to increase access to healthcare, education and economic opportunities for the local population, pursuing the aim of improving their livelihoods; however, this was not accomplished. Populations in more remote areas still have less access to such services and support and, because they are paid by debit card they must travel further to benefit from payments. Thus, this case has a 'low' intensity rating because participation was voluntary, there 
was significant focus on participation but a limited focus on inclusivity, no focus upon marginalized groups and no emphasis on equity or increased rights of local people over resources.

Embeddedness. The project was implemented by the Sustainable Amazonas Foundation in partnership with Amazonas State Secretariat of the Environment and Sustainable Development following global and national interest in REDD+. The project also builds on Bolsa Floresta, a pre-existing payments for ecosystem services program run by the Brazilian government and on Amazonas' interest in more sustainable landuse practices. As such, the MSF is embedded in and coordinated with wider national policies regarding conservation, development, education and health. It is also embedded in and coordinates with international, national and subnational agendas on conservation, climate change mitigation and enhancing the livelihoods of forest-dependent communities. The case has a 'medium' embeddedness rating because it is directly connected to international policies and guidelines, included funding from international sources, and was intentionally integrated with multilevel governance processes. However, it did not include significant structural change of existing institutions.

\subsection{Yalova Model Forest, Turkey - Intensity: Iow / Embeddedness: medium}

The Model Forest program in Turkey was initiated by the General Directorate of Forestry in 2009. All model forests are set up as MSFs to follow principles of collaboration and local participation (IMFN 2006). The first model forest in Turkey, Yalova Model Forest, was established in 2010 (Bekiroglu et al. 2016). Nearly all the forests in Turkey (99\%) are owned by the state and managed by the General Directorate of Forestry.

Intensity. Turkey has signed up to international agreements and pledged to follow the principles of sustainable forest management. The government has also established a National Forestry Program that provides for more participatory and transparent forest resource management, and improved communication on the processes and decisions related to forests and their resources. It also promotes development and poverty reduction in forest communities. The Yalova Model Forest Association was established as an MSF within a system of official institutions, which included associations and people from Yalova Province. However, incorporation of stakeholder views into the Model Forest's management plan was limited, as was involvement of civil representatives in the Association's management body. While Yalova Model Forest was largely established to address conflicts due to land-use issues, the goal of including people and institutions in the Yalova Model Forest Association has not addressed equity or empowered local and/or marginalized people. The case is given a 'low' intensity rating. While it formed a regional public policy group that technically includes all people from the region with binding agreements and some resource sharing, there was little to no focus on addressing inequalities and targeting marginalized groups.

Embeddedness. All model forests must follow criteria set by the International Model Forest Network. Yalova Model Forest was set up with the support of the central and regional governments and all the institutions and people in Yalova Province are automatically considered stakeholders in the Yalova Model Forest Association. Therefore, the program is meant to be integrated with government, civil society and businesses, and has potential for a relatively higher level of embeddedness. However, the case is only given a 'medium' embeddedness rating despite its high potential. The MSF was directly connected to the network of model forests, was integrated with multilevel processes of governance and included the formation of a new governance institution. However, the process and institution were controlled by government agencies, which did not consider equity or increasing participation among marginalized groups as an objective.

\subsection{Hin Nam No Protected Area, Lao PDR - Intensity: medium / Embeddedness: medium}

In the 1990s, Lao PDR implemented laws to establish and manage protected areas. However, it faced a number of challenges, including corruption at different levels, limited information sharing, lack of trust between villages and government officials, and government reluctance to decentralize 
decision-making. To address this, the German government, Lao PDR's Forest Department, and its provincial- and district-level counterparts implemented a project to share resources and build more inclusive decision-making processes. The project, piloted at Hin Nam No Protected Area, organized a multi-stakeholder district comanagement committee.

Intensity. The MSF was comprised of government and village representatives who came together for consensus-based decision-making and to provide oversight and strategic direction for Hin Nam No's pilot collaborative governance system. This included formulating a management plan for the protected area and granting villages an officially recognized mandate to protect and manage resources within and surrounding it. Moreover, the monitoring and management of Hin Nam No is carried out with recognition of local people's customary rights, with clear access and use rights and established mechanisms for addressing infringements. Additionally, over a hundred officially recognized village rangers have been trained and participate in regular monitoring and evaluation processes. A major issue, however, is gender equity. Only 5 of 87 MSF members at the time of the research were women. As such, the case is given a 'medium' intensity rating. It emphasized increasing participation among local people, some resource sharing and binding agreements with ongoing co-management processes, but did not increase their direct control over resources and had a limited focus on equity and increasing the position of women.

Embeddedness. Unlike some of the other cases, there were no local institutions that could be built upon to meet the needs of the program, so Village Co-Management Committees were established. The program was successful in establishing official institutions at three levels: Village Co-Management Committees; Village Cluster Co-management Committees, and the Hin Nam No Protected Area District Co-Management Committee. These institutions are supported by national frameworks, the district governor's office, and the provincial offices of Natural Resources and Environment. Working groups were later set up under the MSF to discuss varying thematic issues and produce a 5-year strategic Hin Nam No co-management plan, which was then endorsed by the district co-management committee. Some major obstacles facing the project included financial and political sustainability, as multilevel coordination requires political will and resources. Corruption in the local government and informal resource extraction from the protected area are still issues that are difficult to fix, despite some improvements. To address such issues, a series of actions were taken, including establishing a capacity-development workshop for government and community members, enacting a policy on affirmative action to make the process more inclusive, and implementing new mechanisms for establishing formal agreements regarding the mandate and terms of reference of co-management structures. Overall, the case has a 'medium' embeddedness rating. It was connected to national policies, received support from the regional government, included the creation of a formalized institution of governance and was implemented with support from international organizations.

\subsection{Bangkok Urban Green Space, Thailand - Intensity: medium / Embeddedness: medium}
This initiative sought to facilitate local participation in a project to transform vacant land in impoverished areas in Bangkok into urban green spaces. It was funded by the Canadian International Development Agency, the Thailand Environment Institute and the International Centre for Sustainable Cities.

Intensity. The project sought to address power imbalances by increasing the participation of different actors who could provide meaningful input and guidance to build sustainable and equitable management of these new green spaces. The project used research, educational workshops and demonstration projects to facilitate mutual learning among stakeholders, develop the capacities of communities concerning environmental issues, reduce poverty, create connections with government, empower women and build a model for replication elsewhere in Bangkok. The project successfully positioned community members as owners of the process and supported them by including urban greening experts. The MSF's objective of empowering women was not immediately successful but achieved through adaptation; there was equal gender representation at all events by design. Furthermore, community participants volunteered 100 person-days 
of labor to the project, building gardens that provided $10 \%$ of household food requirements. The case is given a 'medium' intensity rating as it emphasized participation with a focus on empowering local people, addressing inequalities and supporting marginalized groups in the ongoing management of a green space which local people had rights over. However, there were no binding agreements or a focus on addressing unequal power relations among the project members.

Embeddedness. The project responded to policies set out by the Bangkok Metropolitan Administration to increase green urban spaces and therefore had the support of different levels of government. NGO workers also actively engaged urban planners from local government and involved them with communities. After completing the pilot phase, the project was expanded to approximately 50 other areas, but the model was not as successful due to a lack of commitment among participants. This may result from the failure to incorporate support mechanisms into follow-up mechanisms. Additionally, the potential for replicating the project was challenged by a lack of commitment for funding and full participation among local governmental offices, which were key success factors in the pilot. The case is given a 'medium' embeddedness level as it was integrated with processes of government policy at the city level, was funded and implemented by international organizations, and entailed the formation of a managing institution that coordinated with government agencies. However, there was limited scope for the MSF to impact wider processes related to equity, participation, and empowerment.

\subsection{Ashaninka Communal Reserve, Peru - Intensity: medium / Embeddedness: high}

\section{The Ashaninka Communal Reserve was} created in 2003 in Peruvian Amazonia. There are 20 Ashaninka and 2 Kakinte Indigenous communities in the reserve's buffer zone.

Intensity. The reserve was created with limited government interest to include local people in decision-making processes and allow them direct control over forest resources. This was challenged by local leaders who eventually gained support from international NGOs. Thus, the case's intensity changed throughout its development due to the creation of alliances that emphasized the inclusion of Indigenous Peoples in the reserve's management. As a result, local leaders and partner organizations were able to play a more significant role in the program and gained greater control over decision-making. This offers a counterexample to Hekluskogar, in which local stakeholders were initially included as central to the decision-making process and then marginalized as the government took control over the program. The case has a 'medium' intensity rating because it has a participatory approach with some focus on equity, included some resource sharing, entailed the negotiation of limited increases in rights to resources, and includes a partnership for ongoing co-management processes. However, this partnership and co-management process is not fully equitable because the government retains the ultimate decisionmaking power and, as mentioned, the government has a limited interest in including local people and therefore international NGOs give the most support to the MSF.

Embeddedness. Communal reserves were officially established within Peruvian Law in 1997, opening new avenues for Indigenous Peoples to participate in the governance of areas they considered as part of their traditional territory. Such areas are co-managed by an organization representing Indigenous communities, which enters an official partnership with the National Service for Protected Natural Areas (SERNANP). Thus, from the outset, the project was embedded in a national framework for Communal Reserves and included the participation of multiple levels of governmental, grassroots and NGOs. An important outcome of the shifting of control was that grassroots Ashaninka organizations were able to position themselves as powerful actors in the process of establishing the reserve's management plan. Thus, using their technical knowledge, international network, and locally developed methodology, grassroots organizations were able to co-opt the process of producing the reserve's master plan. In 2010, SERNANP invited the Ashaninka Organization for the Ene River to present their work to the group establishing other similar reserves. Thus, this case has a 'high' embeddedness rating as it included structural changes to existing institutions and was directly connected to wider initiatives with the objective of increasing participation in decision-making and control over resources. 


\subsection{Dwebe Project, South Africa - Intensity: low / Embeddedness: medium}

In the early 20th century, South Africa's

Department of Agriculture, Forestry and Fisheries

removed local peoples from both Dwesa and

Cwebe forests to support the establishment of hotel and holiday cottages for tourists. Local peoples, however, retained access rights to forest products, marine resources and limited use for grazing until 1978, when the Dwesa-Cwebe Nature Reserve was established by the Transkei Homeland Government. In the early 1990s, leaders from two affected villages were brought together by two NGOs Transkei Land Service Organization and the Village Planner - to initiate a claim to regain concessions from the conservation authority. The department opened negotiations a few years later after protests. Established in 1996, the Dwebe Project MSF was a negotiation platform between local communities and the government.

Intensity. The MSF took a win-win approach to negotiations, prioritizing mutually beneficial solutions. However, local leaders were skeptical of the process as the governmental institution present, the Eastern Cape Nature Conservation, did not have decision-making power over their land claim. In 1997, due to a lack of progress on the land claim, local communities pulled out of the MSF, called for its suspension, and asked to meet with the Minister of Land Affairs. He visited the region to meet with local leaders and stated that he supported their claims and that the government would follow through with the land transfer. Yet, when the management of the reserve was transferred to the Eastern Cape Tourism and Parks Authority in 2001, the latter canceled all the villagers' land harvesting rights. In 2009, some rights were restored, but other problems continued as the local government had spent most of the funds for the restitution payments on meetings and planning without consulting local communities. While, early on, a group of partners focused on villagers' land claims, empowerment and authority over resources, the MSF - intentionally or not - fragmented the concerned stakeholders and diluted that focus over time. Therefore, this case is given a 'low' intensity rating because it emphasized increasing participation with little to no focus on marginalized people, and established a binding partnership that included an official local institution, which entailed coordination between different stakeholders.
Embeddedness. The case takes place throughout the collapse of the apartheid era in South Africa, when the government had undeveloped mechanisms for post-apartheid land restitution. NGOs attempted to fill some of those gaps. Over time, the Dwebe Project became increasingly comprehensive in its interconnections with other local and state actors. Eventually, the project translated into an institutional agreement that formalized local communities' relationships with forests. However, the envisioned level of institutionalization was not fully realized, as the Cape Tourism and Parks Authority reversed key gains made by villagers. This MSF is particularly interesting because of the way that the land claim was incorporated into its early stages, but not included in the goals or ambitions of the MSF itself. By emphasizing a win-win methodology to conflict resolution, the Dwebe Project ultimately reduced the local villagers' ability to negotiate. This case shows how MSFs can be disempowering, especially when existing structural conflicts are positioned as problematic issues that need to be isolated and mitigated rather than as opportunities for building a new consensus on resource management. Had the MSF fully incorporated the land claim, it may have resulted in a deeper level of institutionalization in terms of formalizing relationships between rights, responsibilities and joint management. Overall, the case has a 'medium' embeddedness rating as it entailed some negotiation to increase local people's resource rights, even if this was undermined as the process evolved. Moreover, while it was not based on a governmental mandate, it was directly connected to wider governance processes related to institutional changes surrounding rights to land and resources.

\subsection{The Makuleke Claim, South Africa - Intensity: low / Embeddedness: medium}

The Makuleke Claim is located in the north of Kruger National Park. Over the 20th century, there were increased restrictions on local people's use of the national park until the Makuleke were forcibly removed from the area in 1969. The community began organizing a land claim in the 1990s.

Intensity. As with Dwebe, there was an initial focus on villagers' land claims, empowerment and authority over resources. These land claims were formulated differently from Dwebe as the 
Makuleke community connected their land claim to economic development and the establishment of a joint tourism project with a private game lodge operator. In 1995, the Makuleke Ecotourism Project was formed with support from the German Society for Technical Cooperation (GTZ) to formulate jointly, and eventually implement, a plan to use the claimed area for the benefit of both the game lodge and Makuleke communities. The Makuleke Ecotourism Project became a mechanism for coordinating a land restitution plan for the claimed areas between four key stakeholders in the region: Group for Environmental Monitoring, the Minister of Land Affairs, the private game lodge operator, and the Makuleke community. However, the National Parks Board rejected the land claim component of the ecotourism project. As a result, GTZ re-evaluated the project and repositioned its focus from supporting land restitution to facilitating negotiations. Hopeful that they might achieve results with respect to their land claim, Makuleke people participated in dialogue, but eventually requested support from NGOs to pursue their land claim. After 18 months of negotiations, an agreement was formalized that allowed for the claimed area to be co-managed by the South African National Parks and the Makuleke to be used for conservation and related commercial activities. The intensity of this MSF transformed over time as international organizations and government agencies emphasized conservation and conflict mediation through dialogue over the rights and empowerment of local people. Therefore, the intensity of the MSF at the outset was high, emphasizing the recognition of local people's rights, but decreased as the process unfolded. Thus, this case has 'low' intensity because it placed some emphasis on inclusivity with nominal focus on marginalized groups, and entailed the establishment of a local institution that entered a co-management partnership with government that included limited resources sharing, but no recognition of rights over the land.

Embeddedness. As with Dwebe, a key shortcoming with this MSF was that it initially brought together stakeholders that did not have the authority to decide upon or adjudicate land-use claims. Similar to Dwebe, Makuleke local peoples' pursuit of a land claim was undermined by the way that the MSF was organized and the objectives that were prioritized. There is a clear moment when the coordinating organization, GTZ, shifted the emphasis away from empowerment and local land rights and toward dialogue and developing win-win solutions among stakeholders. This, in turn, created a pathway for a participating stakeholder, the National Parks Board, to wield control over the overall process and undermine villagers' claims. This case is given a 'medium' embeddedness rating as it entailed some integration with multilevel processes of governance with international funding support and the involvement of local and international NGOs, but no structural changes or increased local participation in control over resources were observed. Moreover, while it was not based on a governmental mandate, it was connected to wider governance processes related to institutional changes surrounding land and resource rights.

\subsection{Agama Forest Cooperative, Ethiopia - Intensity: medium / Embeddedness: high}

Community forest management was initiated in Ethiopia in the 1990s as participatory forest management. The Bonga forest was one of the earliest experiments, initiated by the UK-based NGO, Farm Africa. Agama is a village comprising four hamlets within the Bonga forest. The forest itself was established as part of a larger program called the Bonga National Forest Priority Area, responding to a wider plan to create large areas of forest in different parts of the country. The process included taking private land and evicting farmers, which led to resentment and hostility between local communities and the government.

Intensity. Funded by the European Union and the UK's Department for International Development, Farm Africa embarked on a demarcation program to address conflicts by creating a more participatory process that included government agencies, experts and local community representatives (including women, elders, and minority groups). Thus, the MSF had a high intensity of emphasis upon addressing power differentials, empowering local people and increasing participation among marginalized groups. However, the demarcation process increased tensions among local people due to historical conflicts over land access and ownership. To address these tensions, the organizers shifted their objectives by setting up projects to increase and enhance livelihoods. Programs were established to increase production, decrease population growth through reproductive health training, and manage resources more sustainably. Over time, the 
emphasis upon reproductive health and increasing sustainable production led to local people being 'beneficiaries' of outside support rather than active participants in the management of forest resources. Overall, the case has a 'medium' intensity rating because it was based on a mandate for increasing participation with a focus on addressing inequalities and empowering local people, included recognition of some customary rights giving local people more rights over resources, and was set up as an ongoing co-management governing process. However, local participants' knowledge was not adequately considered. This case highlights the problematic relationship between the responsibilities placed on local people versus the few rights and control gained by their participation. The case exemplifies how emphasizing livelihood projects and capacity development positioned Farm Africa as the provider of knowledge and resources, which positioned local peoples as beneficiaries rather than partners. This undermined the project's original objectives.

Embeddedness. This was one of the first participatory forest management projects in Ethiopia and was established following the new national legal frameworks. This MSF offers an example of a relatively high embeddedness, as it was connected to wider processes at local, regional, national and international levels that sought to increase local people's control over and participation in the management of forest resources. However, the MSF had unstable funding and suffered from bureaucratic delays at upper levels of the program. This case also points to the problem with connecting foreign agencies with national and regional programs, particularly when international support is unstable or withdrawn. The case has a 'high' embeddedness rating. It implemented structural changes to existing governance, was connected to wider projects/programs with the objective of increasing participation, placed emphasis on addressing inequalities and empowering marginalized groups, and increased participation in decision-making and control over resources. In addition, it included funds for livelihoods projects.

\subsection{Ntchisi Forest Reserve, Malawi - Intensity: high / Embeddedness: high}

The Ntchisi Forest Reserve was established in 1924 under British rule, at which time villages were displaced from the area. At the time of research, almost two-thirds of households in the area were defined as 'poor or very poor', with high dependency on forests and forest resources for their livelihoods. In 2003, an infestation of the speckled emperor moth that attacked trees sparked interest in new approaches to management and protection of the reserve among local people and Malawi's Forestry Department. Nyanja, the community included in this case, has a history of participation in community development projects and existing development institutions that integrate traditional leadership and democratic local governance. The Improved Forest Management for Sustainable Livelihoods Program targeted forest reserves and their adjacent communities across Malawi. To implement it, two frameworks for forest management were set up: Forest Reserves (owned by the government) and Village Forest Areas (owned by communities). The demarcation of Forest Reserve blocks and Village Forest Areas drew boundaries around areas that fell under a broad and tiered system of forest governance and co-management. The objective of the new legal framework was to integrate co-management of both areas to build organizational structures, strengthen local systems of management and facilitate real community participation.

Intensity. Overall, the Improved Forest Management for Sustainable Livelihoods Program placed great emphasis upon empowering local people, increasing their access to and control over forest resources, and enhancing their involvement in decision-making processes. In particular, it formalized rights to resources in the reserve, even if it did not pass legal ownership of that area to the local community. The MSF also emphasized empowering local people, although there is no material in the case about how it addressed the inclusion of more marginalized people. Moreover, it mandated increasing participation with a focus on addressing inequalities and empowering local people. It also recognized some customary rights and included an ongoing management framework based on contractual and relatively equitable partnerships, especially in comparison to what had previously existed. As such, this case offers an example of one of the more intensive MSFs in this review, receiving a 'high' intensity rating.

Embeddedness. The project brought together international donors, NGOs, local people and multiple government actors to support the implementation of a new national policy. It built on existing legal frameworks in Malawi to 
expand and integrate a variety of MSFs. Thus, this case offers the best example of a high value of embeddedness in both design and implementation - and it was relatively successful. In particular, the donor agencies' requirement that the second phase of the project include a licensing and benefit-sharing component led to positive outcomes. However, this did not result in financial gains for the community as commercial firewood production failed due to lack of access to a market. Despite satisfaction with the system for benefit-sharing and commercial projects, overall satisfaction with case incentives for participation was low. One reason for this was that cash-based incentives tended to hurt the poor.
Moreover, an emphasis on economic benefits led to a system of dependency with many participants, nearly $75 \%$, still seeing the government as responsible for their development. Still, most people were more satisfied with the conservation of forest resources and the more equitable rightsbased access brought by the project. Overall, this case had a 'high' embeddedness value as it was directly connected to wider initiatives to increase local participation, decision-making and control over resources. It also placed emphasis on addressing inequalities and empowering marginalized groups. In addition, it entailed some structural changes within government agencies.

Table 3. Classification of MSF case studies based on their intensity

\begin{tabular}{|c|c|c|c|c|c|c|c|c|c|c|c|c|c|c|}
\hline Value & Intensity & 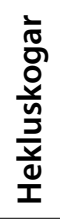 & 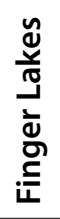 & $\frac{3}{n}$ & 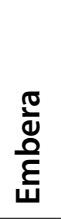 & 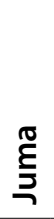 & $\frac{\pi}{\frac{0}{\pi}}$ & 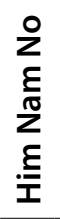 & 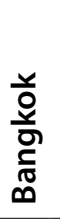 & 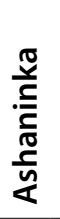 & $\begin{array}{l}0 \\
0 \\
0 \\
0\end{array}$ & 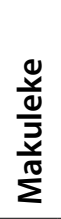 & 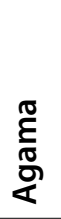 & $\begin{array}{l}\frac{\bar{n}}{\mathbf{U}} \\
\frac{U}{z}\end{array}$ \\
\hline \multirow{7}{*}{ Nominal } & Voluntary participation & & & $\mathrm{X}$ & & $x$ & & & & $X$ & $X$ & & & \\
\hline & Limited scope for increasing inclusion & $X$ & & & & & & & & & & & & \\
\hline & No mention of inequalities & & & $X$ & & $\mathrm{X}$ & & & & & & & & \\
\hline & Short-term & $X$ & & & & & & & & & & & & \\
\hline & $\begin{array}{l}\text { Informal and non-binding conflict resolution, } \\
\text { problem-solving }\end{array}$ & $x$ & & & $x$ & & & & & & & $\mathrm{X}$ & & \\
\hline & Local knowledge not taken into account & & & & & & & & & & & & $X$ & \\
\hline & Emphasis on increasing participation & $X$ & $\mathrm{X}$ & & $X$ & $\mathrm{X}$ & $X$ & & & $X$ & & & & \\
\hline \multirow{4}{*}{ Low } & Establishment of partnerships & & & & & & & & & & $x$ & & & \\
\hline & Coordination & & $X$ & & & & & & & & $\mathrm{X}$ & $X$ & & \\
\hline & Collaboration & & $x$ & & & & & & $x$ & & & & & \\
\hline & $\begin{array}{l}\text { Limited emphasis on equity and empowerment } \\
\text { and nominal recognition of rights }\end{array}$ & $\mathrm{X}$ & $\mathrm{X}$ & & & & & & & & & & & \\
\hline \multirow{5}{*}{ Medium } & $\begin{array}{l}\text { Specific measures for inclusivity and increasing } \\
\text { participation }\end{array}$ & & & & & & & $\mathrm{X}$ & $x$ & & & & & \\
\hline & Co-management & & $x$ & & & & & $\mathrm{X}$ & $\mathrm{x}$ & $x$ & & $\mathrm{X}$ & & \\
\hline & Some focus on equity and empowerment & & & & $\mathrm{X}$ & & & & & & & & $\mathrm{X}$ & \\
\hline & Negotiated restricted rights to resources & & & & & & & & & $x$ & & & $x$ & \\
\hline & Some resource sharing & & & & & & & $\mathrm{X}$ & & $X$ & & $X$ & & \\
\hline \multirow{7}{*}{ High } & Focus on empowerment & & & & & & & $\mathrm{X}$ & $x$ & & & & $x$ & \\
\hline & Focus on addressing inequalities & & & & & & & & & & & & $\mathrm{X}$ & $x$ \\
\hline & $\begin{array}{l}\text { Recognition of some customary rights and } \\
\text { responsibilities }\end{array}$ & & & & & & & $\mathrm{X}$ & & $x$ & & & $x$ & $x$ \\
\hline & Management - Ongoing & & & & & & & & & $x$ & & & $X$ & $\mathrm{X}$ \\
\hline & Contractual and equitable partnership & & & & & & & & & & & & & $x$ \\
\hline & Binding & & & & & & & & & $x$ & & & $\mathrm{X}$ & \\
\hline & Increased rights to resources & & & & & & & & & $\mathrm{X}$ & & & $X$ & $\mathrm{X}$ \\
\hline
\end{tabular}


Table 4. Classification of MSF case studies based on their embeddedness

\begin{tabular}{|c|c|c|c|c|c|c|c|c|c|c|c|c|c|c|}
\hline Value & Embeddedness & 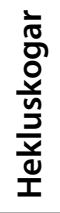 & 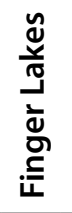 & $\frac{n}{2}$ & 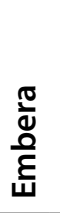 & 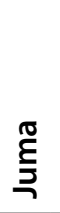 & $\frac{\pi}{\frac{\pi}{\pi}}$ & 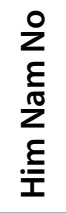 & 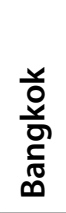 & 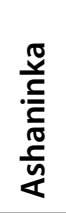 & 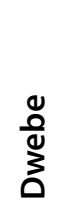 & $\frac{\frac{v}{d}}{\frac{v}{2}}$ & 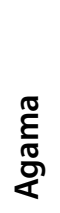 & $\begin{array}{l}\cdot \bar{n} \\
\frac{\bar{C}}{U} \\
\underline{Z}\end{array}$ \\
\hline \multirow{4}{*}{ Nominal } & Focused on a single issue & $\mathrm{X}$ & $\mathrm{X}$ & $X$ & $\mathrm{X}$ & & & & $\mathrm{X}$ & & & & & \\
\hline & Tangential & $X$ & & & & & & & & & & & & \\
\hline & Accidentally nested & & & & & & & & & & & & & \\
\hline & $\begin{array}{l}\text { Connection to single-issue policies and } \\
\text { guidelines }\end{array}$ & $X$ & & $X$ & & & & & & & & & & \\
\hline \multirow{3}{*}{ Low } & Significantly entangled & & & & & & & & & & & & & \\
\hline & Intentionally embedded & & & & & $X$ & & & & & & & & \\
\hline & $\begin{array}{l}\text { Limited connection to wider policies and } \\
\text { guidelines }\end{array}$ & & $\mathrm{X}$ & $\mathrm{X}$ & $x$ & & & & & & & & & \\
\hline \multirow{3}{*}{ Medium } & $\begin{array}{l}\text { Directly connected to wider policies and } \\
\text { guidelines }\end{array}$ & & & & & $x$ & $x$ & $X$ & $X$ & $X$ & & $\mathrm{X}$ & $\mathrm{X}$ & $\mathrm{X}$ \\
\hline & $\begin{array}{l}\text { Integrated with multilevel processes of } \\
\text { governance }\end{array}$ & & & & & $x$ & $x$ & & $X$ & $X$ & $\mathrm{X}$ & $X$ & $x$ & $\mathrm{X}$ \\
\hline & $\begin{array}{l}\text { Creation or formalization of governance } \\
\text { institutions }\end{array}$ & & & & & & $x$ & $\mathrm{X}$ & & & $\mathrm{X}$ & & & \\
\hline \multirow{3}{*}{ High } & Structural and institutional change & & & & & & & & & $X$ & $X$ & & $\mathrm{X}$ & $X$ \\
\hline & $\begin{array}{l}\text { Embedded or connected with wider projects/ } \\
\text { programs focused on participation }\end{array}$ & & & & & & & & & & & & $x$ & $\mathrm{X}$ \\
\hline & $\begin{array}{l}\text { Changes in local participation in decision-making } \\
\text { and control over resources }\end{array}$ & & & & & & & $x$ & & $x$ & $\mathrm{X}$ & & $X$ & $X$ \\
\hline
\end{tabular}




\section{Discussion}

We contribute to closing the evidence gap in the literature on MSFs by presenting an approach to compare how different forums on land use and land-use change address equity. The approach elaborates two key dimensions: the degree to which an MSF includes local peoples as part of a forestlandscape solution and addresses issues of equity, inequalities, power, etc. (intensity); and the degree to which an MSF is part of or connected to wider societal and institutional structures and processes (embeddedness). This discussion is organized in six sub-sections that address different aspects of the case studies, our method of analysis, findings and insights stemming from the literature. We begin with a summary of the findings.

\subsection{The outcome of the combination of different degrees of intensity and embeddedness depends on the context in which MSFs are implemented}

As we explain in more detail in the following section, one of the main challenges of our research was the limited data availability on the design and implementation of MSFs. This means that it is difficult to draw concrete conclusions on direct connections between intensity, embeddedness, and the medium- or long-term outcomes of the MSFs we have reviewed. However, there are lessons concerning the methodology of analysis we have developed, as well as its effectiveness in moving beyond assessments of whether an MSF was successful or not, as is often the case in the literature. We argue that intensity and embeddedness provide a useful conceptual tool for more explanatory and insightful conclusions as to how and why MSFs have particular outcomes. To accomplish this we set out a series of patterns for how intensity and embeddedness interact and impact one another and provide evidence to support our analysis (see Figure 2). For each of the patterns or permutations, we explain why the patterns can lead to different outcomes and how this occurs. Since we used a small number of cases to develop this framework, there may be other relationships not seen here. In general, these cases are more proof that 'context matters' when it comes to participatory processes and their impact (Sarmiento Barletti et al. 2020).

The first option is high intensity and embeddedness. We propose that an MSF with this combination of intensity and embeddedness will help to address power inequalities beyond the MSF itself. For example, in Ntchisi (the only case study with high intensity and embeddedness) and Agama (medium intensity and high embeddedness), there was a change in forest management, including more local participation and control over resources. While there were issues with Ntchisi, it had some meaningful successes that can be understood as resulting from an emphasis on equity and participation both within the MSF and in the wider context of governance. Him Nam No had a medium level of intensity because of its strategies to address inequality, and a medium level of embeddedness because of its interconnections with wider policies and institutional changes that sought to increase local participation in the management of protected areas. In this case, the equitable approach was able to impact the wider context thanks to its embeddedness, permitting local peoples' access to forests and resources. Similarly, Bangkok had a medium level of intensity and embeddedness, which led to enhanced citizen participation in urban forestry planning. However, the application of the same MSF elsewhere had less positive outcomes when there was insufficient funding and support for participation from government actors. Furthermore, most of the case studies in our review with medium or high levels of embeddedness tended to have medium or high intensity levels. In these cases, there 


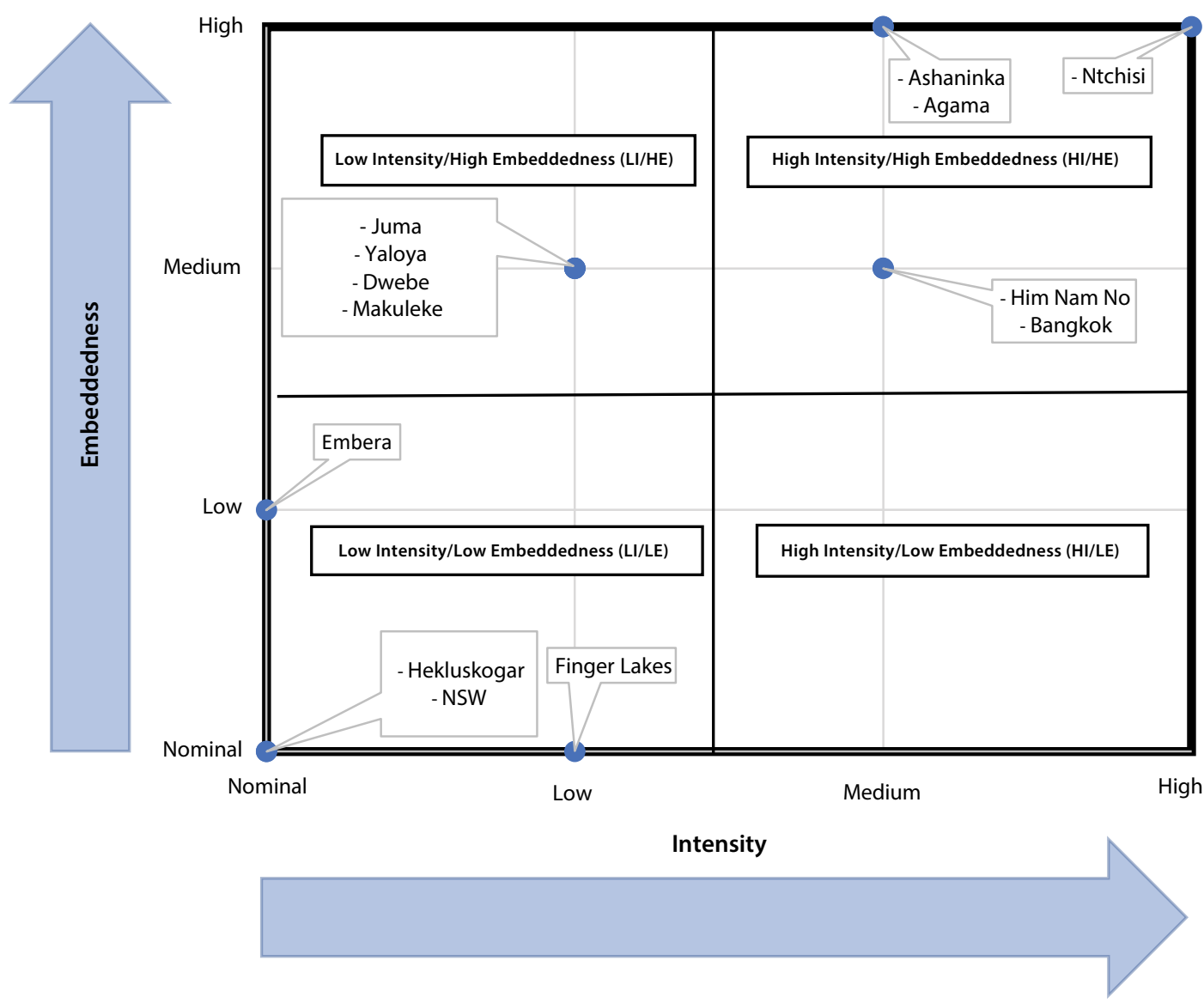

Figure 2. Visual summary of intensity and embeddedness by case study

were embedded in institutional contexts that were supportive of more equitable processes. This leaves the question of what would result from an MSF with high intensity and embeddedness in a highly unequal context that is not open to equity concerns, which could potentially lead to changes limited to the MSF's immediate area of action or could negatively affect equity in the MSF and greatly diminish any potential for positive outcomes beyond.

The second option is low intensity and high embeddedness. Our wider research on MSFs showed how forums that were highly embedded in broad contexts of relative equality may only need low or medium intensity to achieve equityrelated goals (see Gonzales Tovar et al. in press). A highly embedded MSF in a context of inequality, however, may not have a wider impact if it places little or no importance on changing the status quo by addressing power inequalities (low intensity). In our review, MSFs with low intensity and medium embeddedness levels were organized in contexts marked by unequal structures. Finding these contexts challenging, MSF organizers changed their goals to what seemed like more plausible pathways to positive change, but which ended up being detrimental to the priorities of local communities. The shift in the MSF priorities undermined the local communities' land claims in Makuleke and reduced local villagers' ability to negotiate their land rights in Dwebe.

The third option is an MSF with low embeddedness and high intensity. In this case, even if the MSF is equitable and seeks to address power structures (high intensity), this would not enable changes in power relations outside the MSF (low embeddedness). This scenario was not found across the case studies. When there were low embeddedness levels, even when some measures were taken to improve equity (e.g. Yalova), inequalities remained as there were no structural changes.

The fourth option is low intensity and embeddedness. In these cases (e.g. cases 1-4), MSFs did not seek to address inequalities (low intensity) and had little connection with wider 
processes and institutions (low embeddedness). Hekluskogar, Finger Lakes, and NSW were initially established as part of wider government trends to increase participation of local stakeholders in establishing plans for protecting natural resources. In NSW, however, the MSF's potential to reach its goals was hindered as the planning process was centralized around inputting data into a new program that the fire protection service designed and controlled. As a result, many stakeholders were included in the planning process as participants, but it seems that their primary role was to provide their knowledge, which was collected and organized by the fire protection service. Similarly, the MSFs in Hekluskogar, Finger Lakes and Embera did not address power differentials and had a marginal inclusion of stakeholders. These cases focused on a single issue and were not entangled with wider processes; therefore, they did not lead to any structural changes. Furthermore, Embera highlights the importance of government involvement to improve embeddedness and have an impact on the wider context.

\subsection{There are limited data on processes, outcomes and medium- and long-term impacts of MSFs, highlighting the need to publish more details}

Throughout the cases studied, there are limited data on the actual planning and execution of the MSFs (e.g. Hekluskogar and Finger Lakes). Many of the articles reviewed had limited information from interviews with organizers and/or participants, while some did not include any interviews at all. Furthermore, for most case studies, there were limited official data about how the project was developed, funded and implemented. Overall, there was little detail regarding how processes within MSFs were designed and ran. For example, some cases include general statistics or numbers of the people and groups who participated, but details regarding how they participated were sparse, generalized or not included. Additionally, while some cases provided an assessment of whether a project fulfilled its objectives or not, this is often framed in broad terms with limited explanation for how and why things worked out the way they did. For example, none of the case studies evaluated environmental indicators in a comprehensive or systematic manner.

A general problem identified in the literature about MSFs, particularly those at the subnational level, and projects that include MSFs as part of their methodologies, is that few studies provide substantial research on the context prior to an MSF's introduction and details about its implementation. Even in cases where extensive fieldwork has been carried out (e.g. Ashaninka), there is limited published research that follows up a year or more after the initial research was done. In other cases (e.g. Hekluskogar, Finger Lakes, NSW and Bangkok), there seems to have been one period of research and no follow-up to assess the actual outcomes of the MSFs over time. Furthermore, while this limitation is problematic, the most glaring gap identified in this and previous research (Sarmiento Barletti et al. 2019, 2020) is the lack of literature based on long-term studies of MSFs. Thus, while Ashaninka does offer some material, it is limited.

One reason for this knowledge gap is that the boom in MSF implementation has not been matched by the same degree of interest in research on these cases. Furthermore, some organizations with extensive experience implementing and monitoring MSFs do not publish material with sufficient detail about their MSFs' processes or evidence to substantiate their findings about their work. These same organizations often argue that there is insufficient material available to provide evidence for whether MSFs are truly successful, how and why (see Sarmiento Barletti et al. 2019). A third issue is the selectivity of the data, as much of the information on MSFs is published by their organizers, who may not be as willing to, or interested in, presenting their failures. This lack of knowledge sharing greatly reduces the ability to evaluate long-term impacts of MSFs or projects that include MSFs as a component. These issues lead to an overall lack of long-term crossdisciplinary studies that examine connections between MSFs, participation (equity), economic outcomes, and changes in conservation and biodiversity. As we noted in the previous section, this means that there is insufficient evidence to evaluate whether higher embeddedness or intensity leads to better outcomes and impacts beyond the research period. 


\subsection{Lessons for methods and research processes}

A practice-based approach is promising for studying MSFs. For example, Agama employs this research methodology, which emphasizes understanding the ways in which local people experience processes and make decisions. In fact, four of the most detailed cases (Ashaninka, Dwebe, Makuleke, and Agama) all engage with this in similar ways and provide the most useful materials for understanding the case studies. In these cases, the issues of power, representation, decisionmaking processes and outside influences were all directly addressed in ways that allowed for more detailed and nuanced understandings. Given the overall paucity of evidence about how decisions are made in these processes, these cases offer important guides for the approaches needed to fill knowledge gaps. Behagel et al.'s analysis of Agama notes that:

a practice-based approach is able to offer nuanced
and empirically grounded accounts of political
struggles and democratic practices. Its potential
is especially strong in cases where policy-making
and policy ideas and outcomes are less clearly
linked to argumentative processes. We conclude by
arguing for further inclusion and consolidation of
practice-based approaches within the tradition of
interpretive policy analysis. $(2017,1)$

Participatory research offers another promising method for studying MSFs. For example, in Embera, the authors partnered with local people to improve a project that they supported but did not organize; they include this engagement in detail in the article. Bangkok includes some details about the MSF's process, although little detail is provided on how women experienced their changing involvement in the project. This raises a point about Ashaninka as the author carried out more than a year of fieldwork, but also supported local people's efforts to make the process more representative of their concerns and objectives. As such, the details provided stem from a participatory approach that produced a nuanced account of the ways stakeholders engaged, the slow process of shifting power dimensions and the struggle to build equity into the management system.

These cases demonstrate that people engage in MSFs for their own reasons and have their own objectives. The details they include, however, point toward the need to transcend approaches which only gauge people's positions or experiences after the fact, and instead document MSF processes in detail. While some cases (e.g. Yalova) give details concerning the legal frameworks and structures of the MSF, they omit important information about its process. This information would allow for deeper analysis of the reasons why the project was unsuccessful even though people were willing to participate. That is, the ways people engage with an initiative and its context are not easily accounted for by extrapolating from their willingness to participate; hence, the importance of detail on processes. Participants' perspectives and decision-making processes are complex and need to be explained and understood to improve the effectiveness of MSFs. This point is made by Ayana et al.:

although [participatory forest management] projects might be well designed in terms of general principles of robust institutions, their effectiveness still remains to be seen given the fact that people might act upon the new incentives, rules and norms differently than expected, or not at all, given their local, situational logics of action. $(2017,3)$

The details about local people's decision-making, regarding what they prioritize and why, are insightful. This same kind of detail can and should be extended to descriptions and discussions about those leading the project so that the decision-making processes of the organizers is not taken for granted (see Sarmiento Barletti et al. in press for a study of MSF organizers' perspectives). This raises the question of how much information is included when those responsible for a project are also authoring articles. For example, in Ntchisi, the author makes an interesting point about the process and how it was unable to adapt to problems and local people's interests. While experiential learning was meant to be a component of the project, this was undermined by inadequate information and the failure to incorporate social learning processes directly into co-management implementation. As the author points out, "[s] elf-reflection was episodic, inadequate, and largely dependent on external reviews, studies or consultancies, and 'passive' analysis of inadequate monitoring and evaluation reports that emphasized quantitative indicators at the expense of qualitative and process-based ones or participatory monitoring." (Zulu 2013, 1928). 


\subsection{The objectives of MSFs change over time}

The objectives set out at the beginning of an MSF do not always end up being those that are prioritized, as priorities and collaboration arrangements change through time. For example, in Hekluskogar the government initially sought to address the imbalances of the status quo top-down approach by applying new participatory methods. This resulted in the establishment of the MSF, which successfully brought different actors together and obtained funding for the project. Priorities seem to have changed since then toward knowledge sharing, as the government took complete control of the project, undermining the potential to increase participation both within the MSF itself and in the wider processes implementing conservation and land restoration projects. Additionally, this decision resulted in a reduction in both the MSF's intensity and embeddedness. There was a different kind of transformation in Dwebe and Makuleke as different kinds of MSFs emerged to deal with land claims and resource management. While these two processes sometimes overlapped, they were not fully integrated with one another due to an NGO's reluctance to get involved and the unwillingness of local leaders to integrate their land claims with a process that would not prioritize them over conservation objectives. As such, there were multiple simultaneous MSFs, each with different primary objectives. Ashaninka offers insights into a different kind of shift, one in which NGOs were able to integrate a government-led process with their goals of building a more inclusive and accountable system of governance.

\subsection{Implementation matters - Designing a participatory process to be equitable is not enough}

The case studies show that having a design or intent that focuses on addressing power inequalities is important but is not enough. Some of the cases provided evidence of how thoughtful design was undercut, and/or how the intent of addressing these issues was de-prioritized, in implementation. For example, the government mandate under which NSW was established sought to enhance participation and address inequalities, but this was not reflected in its implementation. Rather, in practice it side-stepped power inequalities instead of addressing them directly, and the focus on assets and technical knowledge diminished a potentially higher intensity. Similarly, Agama's MSF focused on equity during design, as it sought to represent different social groups as well as support demarcation of rights over resources. However, it was implemented in a way that resulted in increased tensions among local people - most local participants resented, mistrusted and felt alienated by the process. The project's focus shifted to prioritize livelihoods and health projects, transforming local people from MSF partners to beneficiaries of outside assistance. Dwebe demonstrates a similar shift, albeit in a different way. Although the MSF originally focused on empowering villagers and supporting their land claims and authority over resources, the MSF's priorities shifted to seeking a consensus that would reduce conflicts with government and other actors over local people's rights. This created divisions among the concerned stakeholders and diluted the MSF's intensity.

Actors involved in implementing an MSF may impact its planned intensity in different ways. In the cases above - and perhaps to be expected these changes were introduced by some of the most powerful actors. However, sometimes the opposite happens. In Ashaninka, historically marginalized actors created alliances to impact the MSF and improve its intensity. The MSF started with a general focus on including local people in decisionmaking and was transformed by Indigenous organizations and NGOs, which developed a methodology that included local people's perspectives in the management of a protected area and enhanced their position in negotiating the terms of the management agreement. Because this case was so highly embedded in the Peruvian system of Natural Protected Areas, its impact extended beyond its immediate context into higher levels: it improved equity in the management of the Ashaninka Communal Reserve while supporting the legal transition toward comanagement for communal reserves in Peru. This model has received much praise in international conservation forums (see Palacios Llaque and Sarmiento Barletti in press). Importantly, these processes happened in an international context that was supportive of Indigenous Peoples' involvement in environmental management, and in a national context where laws protecting Indigenous rights 
had been in place for more than a decade.

Although we cannot generalize, given the lack of similar examples in our sample, this seems to suggest that historically marginalized actors might be able to flip the issue of power we saw in NSW, Dwebe and Agama, but this may depend on how these actors and their objectives are embedded in wider processes at different levels.

\subsection{Responsibilities need to come with benefits}

As MSFs aim to increase local participation, increased responsibilities for local peoples do not tend to correspond with an increase in resource access or control, or land rights. As was demonstrated by Ashaninka, there was hesitation among Indigenous leaders because the agreement they were meant to sign placed extensive responsibilities on local organizations and communities without providing sufficient support or benefit. Agama is similar, as communities had responsibilities over an extensive array of activities, while gaining little in terms of control over resources. In fact, in these cases, local partners were supposed to increase their regulation of forest resource use and monitor to ensure that there were no infractions based upon the new rules. In contrast, in Ntchisi, local people gained formal access to the reserve, rights to some financial benefits from licensing for access and support in managing their own forests. However, there were no cases where local people received titles to land that had been declared a protected area. While this was the original aim in Makuleke, participants only achieved access rights to the reserve. Consequently, the importance of identifying the balance between rights and control gained, and responsibilities mandated should be incorporated into the concept of intensity. In fact, there are few examples in the literature of cases where full rights over protected areas or forest resources are transferred from private or state ownership to local people. There are, however, many cases in which rights are extended, but with extensive systems of control and management by governmental agencies (Mohanty 2003; Larson and Pulhin 2012). 


\section{Concluding remarks}

This occasional paper examines MSFs based upon two key characteristics: the degree to which an MSF includes local peoples as part of a forestlandscape solution (its intensity), and the degree to which the MSF and its outcomes are part of the societal and institutional fabric of a given area (its embeddedness). The reasons for focusing on these characteristics are simple yet important. First, classifying MSFs as either top-down, bottom-up, or a combination of both is not particularly useful. Second, defining MSFs as either utilitarian or normative is equally problematic. Third, clear gaps in research and analysis on equity in MSFs were identified in the literature (Sarmiento Barletti et al. 2020). Fourth, previous research has found that an MSF's potential to promote greater equity and its long-term sustainability and success are challenged if local peoples are not regarded as key partners and change-makers (and thus more than mere project or initiative 'beneficiaries'), and if the MSF and/or its solutions are not meaningfully institutionalized. Our analysis proves useful in describing cases and explaining how they differ, particularly in terms of equity. Intensity and embeddedness are useful analytical tools that go beyond typologies that identify characteristics found in successful MSFs. They are helpful in terms of explaining how different approaches across different contexts function and add nuance to simplified dichotomies.

The analytical application of intensity and embeddedness to our case studies permitted new insights, demonstrating their value as analytic tools while also pointing toward ways that they could be further developed. Importantly, a major point regarding the analysis of MSFs is that there needs to be sufficient material detailing their processes.
While there are many cases in the literature, there is little material with sufficient detail.

As for the application of these analytical tools and their further development, intensity might be expanded to include a more detailed analysis of the perceptions and experiences of the different stakeholders so it can differentiate between stakeholders participating in the projects at different scales (e.g. funders, organizers, implementers, local people). For example, there are cases where a government or donor policy sets out a framework to increase the rights of local people to participate in decision-making and management of forest resources, but at the level of implementation there is no corresponding commitment to this degree of intensity. As for embeddedness, those assessing and writing about MSFs should find this concept valuable for how they engage in research about the medium- and long-term impacts of MSFs. It is not enough to simply look at an MSF as a closed circuit or single event; to understand the wider potential of MSFs to impact wider sociocultural, economic and political structures, the surrounding institutions, whether formal or informal, should be considered. Ashaninka offers insight on how different stakeholders perceive embeddedness in terms of the ways 'natural resources' are defined. This includes how Ashaninka people understand their territory as part of a living landscape that is inhabited by different kinds of other-than-human beings (Sarmiento Barletti 2016), thus, bringing more actors and 'institutions' into the project. This insight raises the potential for embeddedness to engage with different ways of conceiving what is beyond - but connected to - the project, including the ways in which local people inhabit their landscapes and experience protected areas (West et al. 2006). 


\section{References}

Adger WN. 2006. Vulnerability. Global Environmental Change 16:268-81.

Agustsson K, Garibjana A, Roja E and Vatn A. 2014. An assessment of the forest allowance of the Forest Allowance Programme in the Juma Sustainable Development Reserve in Brazil. International Forestry Review 16(1):87-102.

Ayana AN, Vandenabeele N and Arts B. 2015. Performance of participatory forest management in Ethiopia: Institutional arrangement versus local practices. Critical Policy Studies 15:1-20.

Bastakoti R and Davidsen C. 2015. Nepal's REDD+ Readiness preparation and multistakeholder consultation challenges. Journal of Forest and Livelihood 13(1):30-43.

Backstrand K. 2006. Multi-stakeholder partnerships for sustainable development: Rethinking legitimacy, accountability, and effectiveness. Environmental Policy Governance 16(5):290-306.

Bekiroglu S, Ozdemir M, Ozyurek E and Arslan A. 2016. Opportunities to enhance contribution of model forests in the sustainable forest resources management. Journal of Environmental Management 81:701-9.

Behagel JH, Arts B and Turnhout E. 2017. Beyond argumentation: A practice-based approach to environmental policy. Journal of Environmental Policy \& Planning 21(5):479-491.

Berglund B, Hallgren L and Aradóttir AL. 2013. Cultivating communication: Participatory approaches in land restoration in Iceland. Ecology and Society 18(2):35.

Brummel RF, Nelson KC and Jakes PJ. 2012. Burning through organizational boundaries? Examining inter-organizational communication networks in policy-mandated collaborative bushfire planning groups. Global Environmental Change 22:516-28.

Boyd W, Stickler C, Duchelle AE and RodriguezWard D. 2018. Jurisdictional approaches to
REDD + and low emissions development: Progress and prospects. Working Paper. Washington DC: World Resources Institute.

Caruso E. 2011. Co-management redux: Antipolitics and transformation in the Ashaninka Communal Reserve, Peru. International Journal of Heritage Studies 17(6):608-28.

Caruso E. 2014. State governmental or Indigenous sovereignty? Protected area co-Management in the Ashaninka Communal Reserve in Peru. In Stevens S, ed. Indigenous Peoples, National Parks, and Protected Areas: A New Paradigm Linking Conservation, Culture, and Rights. Tucson, Arizona: University of Arizona Press. 150-71.

de Koning M, Nguyen T, Lockwood M and Phommasane S. 2017. Collaborative governance of protected areas: Success factors and prospects for Hin Nam No Natural Protected Area. Conservation and Society 15(1):87-99.

Fay DA. 2014. Mutual gains and distributive ideologies in South Africa: Theorizing negotiations between communities and protected areas. In Stevens S, ed. Indigenous Peoples, National Parks, and Protected Areas: A New Paradigm Linking Conservation, Culture, and Rights. Tucson, Arizona: University of Arizona Press. 217-40.

Faysse N. 2006. Troubles on the way: An analysis of the challenges faced by multi-stakeholder platforms. Natural Resources Forum 30(3): 219-29.

Gebara MF. 2013. Importance of local participation in achieving equity in benefitsharing mechanisms for REDD+: A case study from the Juma Sustainable Development Reserve. International Journal of the Commons 7(2):473-97.

Gonsalves J, Becker T, Braun A, Campilan D, De Chavez H, Fajber E, Kapiriri M, RivacaCaminade J and Vernooy R, eds. 2005. 
Participatory research and development for sustainable agriculture and natural resource management: a sourcebook. Understanding participatory research and development. Lima: International Potato Center.

Gonzales Tovar J, Larson AM, Sarmiento Barletti JP and Barnes G. in press. Politics, power and the search for sustainability in multistakeholder territorial planning: A comparative study of two contrasting cases in the Brazilian Amazon. International Forestry Review.

Gray B and Purdy J. 2018. Collaborating for our Future: Multistakeholder Partnerships for Solving Complex Problems. Oxford: Oxford University Press.

Haufler, V. 2003. New forms of governance: Certification regimes as social regulation of the global market. In Meidinger E, Elliot $\mathrm{C}$ and Oesten G, eds. Social and Political Dimensions of Forest Certification. Germany: Forstbuch. 237-247.

Hemmati M, ed. 2002. Multi-stakeholder Processes for Governance and Sustainability: Beyond Deadlock and Conflict. Sterling, Virginia: Earthscan Publications Ltd.

Hewlett C. n.d. Internal Review of Systematic Reviews and Maps. Bogor, Indonesia: CIFOR.

Holmes I, Potvin C and Coomes O. 2017. Early REDD+ implementation: The journey of an indigenous community in Eastern Panama. Forests 8(67):1-18.

[ILO] International Labour Organization. 1989. Indigenous and Tribal Peoples Convention (No. 169). The General Conference of the International Labour Organization. Geneva: ILO.

[IMFN] International Model Forests Network. 2006. Model Forest Profiles: 2005. Ottawa: IMFN.

[IPCC] Intergovernmental Panel on Climate Change. 2007. Climate Change 2007: Impacts, Adaptation and Vulnerability. The Working Group II Contribution to the Intergovernmental Panel on Climate Change Fourth Assessment Report. Cambridge, UK: Cambridge University Press.

Kohne M. 2014. Multi-stakeholder initiative governance as assemblage: Roundtable on Sustainable Palm Oil as a political resource in land conflicts related to oil palm plantations. Agriculture and Human Values 31:469-80.

Larson AM and Pulhin J. 2012. Enhancing forest tenure reforms through more responsive regulations. Conservation and Society 10(2):103-13.
Larson AM, Sarmiento Barletti JP and Ravinkumar A. 2018. The challenge of coordination in REDD+ policy and practice. In Angelsen A, Martius C, de Sy V, Duchelle A, Larson A and Pham TT, eds. Transforming REDD+: Lessons and New Directions. Bogor, Indonesia: CIFOR. 81-92.

Mohanty R. 2003. Institutional interface and participation in local forest management in Uttaranchal Innovations. Civil Society $3(1): 3-14$.

O'Rourke, D. 2006. Multi-stakeholder regulation: Privatizing or socializing global labor standards? World Development 34(5):899-918.

Palacios Llaque D and Sarmiento Barletti JP. in press. The challenges of multiple governmentalities and forms of participation in protected natural areas: The Amarakaeri Communal Reserve (Peruvian Amazon). International Forestry Review.

Poncelet EC. 2004. Partnering for the Environment: Multistakeholder Collaboration in a Changing World. London: Rowman \& Littlefield.

Ravikumar A, Larson AM, Myers R and Trench T. 2018. Inter-sectoral and multilevel coordination alone do not reduce deforestation and advance environmental justice. Environment and Planning C 36(8):1437-57.

Sarmiento Barletti JP. 2016. The angry earth: wellbeing, place, and extractive development in the Amazon. Anthropology in Action 22(4):43-53.

Sarmiento Barletti JP and Larson AM. 2019a. The role of multi-stakeholder forums in subnational jurisdictions: Framing literature review for indepth field research. CIFOR Occasional Paper 194. Bogor, Indonesia: CIFOR.

Sarmiento Barletti JP and Larson AM. 2019b. Multi-Stakeholder Forums: Methods Training Manual and Tools for In-depth Research. Bogor, Indonesia: CIFOR.

Sarmiento Barletti JP, Larson AM and Heise NM. in press. Organizing for transformation? Why organizers plan their multi-stakeholder forums. International Forestry Review.

Sarmiento Barletti JP, Larson AM, Hewlett C and Delgado D. 2020. Designing for engagement: A realist synthesis review of how context affects the outcomes of multi-stakeholder forums on land use and/or land-use change. World Development 127:104753.

Sarmiento Barletti JP and AM Larson. 2020. Environmental justice in the REDD+ frontier: 
Experiences from the Amazon and beyond. In Robbins $\mathrm{N}$ and Fraser B, eds. Landscapes of Inequity: The Quest for Environmental Justice in the Andes/Amazon Region. Lincoln, NE: University of Nebraska Press. 167-98.

Sarmiento Barletti JP, Hewlett C and Larson AM. 2019. Protocol for a realist synthesis review: How does context affect the outcomes of subnational multi-stakeholder forums on land-uselland-use change?. Bogor, Indonesia: CIFOR.

Schouten, G, Leroy P and Glasbergen P. 2012. On the deliberative capacity of private multistakeholder governance: The Roundtables on Responsible Soy and Sustainable Palm Oil. Ecological Economics 83:42-50.

Stickler C, Duchelle AE, Ardila JP and Pritchard L. 2018. The State of Jurisdictional Sustainability: Synthesis for Practitioners and Policymakers. California: Earth Innovation Institute.

Sterling E, Betley E, Sigouin A, Gomez A, Toomey A, Cullman G, Maolne C, Pekor A, Arengo F, Blair M, Filardi C, Landrigan $\mathrm{K}$ and Porzecanski A. 2017. Assessing the evidence for stakeholder engagement in biodiversity conservation. Biological Conservation 209:159- 171.
Stringer LC, Dougill AJ, Fraser E and Reed MS. 2006. Unpacking "participation" in the adaptive management of social-ecological systems: a critical review. Ecology and Society 11(2):39.

Tsosie R. 2007. Indigenous people and environmental justice: The impact of climate change. University of Colorado Law Review 78:1625.

Twarkins M, Fisher L and Robertson T. 2001. Public involvement in forest management planning: A view from the northeast. Journal of Sustainable Forestry 13(1-2):237-51.

[UN] United Nations. 2007. Declaration on the Rights of Indigenous People. The United Nations General Assembly. New York: UN.

Warner JF. 2006. More sustainable participation? Multi-stakeholder platforms for integrated catchment management. Water Resources Development 22(1):15-35.

West P, Igoe J and Brockington D. 2006. Parks and peoples: The social impact of protected areas. Annual Review of Anthropology (35):251-77.

Zulu L. 2013. Bringing people back into protected forests in developing countries: Insights from co-management in Malawi. Sustainability 5(5):1917-43. 


CIFOR Occasional Papers contain research results that are significant to tropical forest issues. This content has been peer reviewed internally and externally.

This occasional paper presents a new approach to examining how multi-stakeholder forums (MSFS) on land use and land-use change address equity. Based on a review of cases in the scholarly literature, we engage with MSFs from two key characteristics: the degree to which an MSF includes local peoples as part of a forest-landscape solution (its intensity), and the degree to which an MSF and/or its goals or objectives are embedded or entangled in wider societal or governmental programs and processes (its embeddedness).

Multi-stakeholder forums (MSFs) have been positioned as a transformative solution for more sustainable decisionmaking in forestry, land use, and climate change interventions. Yet, we propose that an MSF's resilience and potential to promote equity is impeded if local peoples are not regarded as key partners rather than 'beneficiaries', and if the forum and/or its outcomes are not meaningfully institutionalized.

Intensity and embeddedness are useful analytical tools that go beyond typologies that identify characteristics found in successful MSFs. They are helpful in terms of explaining how different approaches across different contexts function and add nuance to simplified dichotomies. The analytical application of intensity and embeddedness to the analysis of MSFs permits new insights as they describe cases and explain how they differ in terms of equity.

\begin{tabular}{|c|c|c|}
\hline$\underbrace{16 j}_{\text {CGIAR }}$ & $\begin{array}{l}\text { RESEARCH } \\
\text { PROGRAM ON } \\
\text { Policies, } \\
\text { Institutions, } \\
\text { and Markets } \\
\quad \text { Led by IFPRI }\end{array}$ & $\begin{array}{l}\text { The CGIAR Research Program on Policies, Institutions, and Markets (PIM) leads action-oriented research to } \\
\text { equip decisionmakers with the evidence required to develop food and agricultural policies that better serve the } \\
\text { interests of poor producers and consumers, both men and women. PIM combines the resources of CGIAR centers } \\
\text { and numerous international, regional, and national partners. The program is led by the International Food Policy } \\
\text { Research Institute (IFPRI). www.pim.cgiar.org }\end{array}$ \\
\hline
\end{tabular}

\begin{tabular}{l|l} 
The CGIAR Research Program on Forests, Trees and Agroforestry (FTA) is the world's largest research for \\
development program to enhance the role of forests, trees and agroforestry in sustainable development \\
and food security and to address climate change. CIFOR leads FTA in partnership with ICRAF, the Alliance \\
of Bioversity International and CIAT, CATIE, CIRAD, INBAR and TBI.
\end{tabular}
ping partners' capacity, and actively engaging in dialogue with all stakeholders to inform policies and practices that affect forests and people. CIFOR is a CGIAR Research Center, and leads the CGIAR Research Program on Forests, Trees and Agroforestry (FTA). Our headquarters are in Bogor, Indonesia, with offices in Nairobi, Kenya; Yaounde, Cameroon; Lima, Peru and Bonn, Germany. 